\title{
Studygram: Interação e compartilhamento de processos de ensino-aprendizagem através do Instagram
}

\author{
Raquel M. M. Fernandes \\ Programa de Pós Graduação em Informática (PPGI) - Instituto Tércio Pacitti de \\ Aplicações e Pequisas Computacionais - Universidade Federal do Rio de Janeiro \\ (UFRJ) / Instituto de Ciências Exatas (ICEX) - Universidade Federal Fluminense \\ (UFF) \\ raquelmachado@id.uff.br
}

\begin{abstract}
The objective of this article is to present a pilot project of immersion research around the phenomenon of the Studygram in order to understand it, to correlate it with Neuroscience and Cognitive Psychology to test its educational benefits and verify the viability of intentional use to optimize learning.
\end{abstract}

Resumo. O objetivo deste artigo é apresentar um projeto piloto de proposta de pesquisa de imersão em torno do fenômeno do Studygram a fim de compreendê-lo, correlacioná-lo com a Neurociência e Psicologia Cognitiva para testar seus benefícios educacionais e verificar a viabilidade de sua utilização intencional para otimização da aprendizagem.

\section{Introdução}

Atualmente o Instagram, rede de compartilhamento de fotos e vídeos através da internet, ocupa o sexto lugar no ranking das maiores redes sociais com um bilhão de usuários ativos. Um dos fenômenos que se pode identificar em torno desta rede é o surgimento dos chamados Studygrams, perfis do Instagram cujo objetivo é apresentar fotos e stories sobre o processo de estudo de uma ou mais disciplinas. Esta pesquisa, portanto, apresenta uma proposta de discussão dos Studygrams com um embasamento teórico sugerido a partir das áreas de Computação e Neurociências.

\section{Métodos e desenvolvimento}

Esta pesquisa iniciou-se com a identificação do fenômeno em um grupo da população de usuários do Instagram. O crescimento exponencial dos Studygrams, verificado a partir de observação pontual, motivou a busca por um conhecimento científico sobre o mesmo. Diversas pesquisas recentes já apresentam resultados de ações voltadas para a educação envolvendo as redes sociais e embora o termo Studygram, utilizado pelos usuários, não tenha retornado dados em buscas na literatura nacional, encontra-se estudos recentes sobre a utilização do Instagram na sala de aula, como o de Teixeira(2017) e Barbosa(2017). Os referidos estudos demonstram o potencial da rede para os processos de ensino-aprendizagem; contudo, diferem da pesquisa aqui proposta por não abrangerem explicitamente aspectos extraídos dos Studygrams criados espontaneamente pelos usuários. As pesquisas apresentam ações realizadas intencionalmente no Instagram, mas os resultados que almeja-se reproduzir ainda precisam ser devidamente elucidados e comprovados. Deste modo, é necessário inicialmente conhecermos e compreendermos a importância dos Studygrams para seus usuários nativos, investigar seus benefícios e aspectos intrínsecos para que posteriormente possamos estabelecer relações e comprovar cientificamente as 
VII Congresso Brasileiro de Informática na Educação (CBIE 2018)

Anais do XXIX Simpósio Brasileiro de Informática na Educação (SBIE 2018)

implicações da sua utilização intencional.

A fim de explorar o universo digital no qual o fenômeno emerge, considerou-se a técnica de amostragem de tipo não probabilística por conveniência realizada através da recuperação de dados categorizados por hashtags na rede social em questão.

Esperava-se, com esta técnica, obter informações sobre tendências e resultados que pudessem ser utilizados na compreensão inicial dos agentes do fenômeno em projeto piloto a fim de se estabelecer possibilidades de investigações futuras em que se prezará a utilização de amostras probabilísticas para estudos mais precisos.

Privilegiou-se, portanto, resultados recuperados a partir do indexador \#studygrambr organizados de acordo com os critérios de cronologia da rede social, que retornou 8519 publicações no período de junho-2018. Após a seleção, os usuários foram submetidos através de direct messages a um survey com as seguintes questões: 1 Como você define seu Studygram? 2 - Por que você decidiu criar um Studygram? 3 Por que você decidiu construir seu próprio material de estudo? 4 - Que ferramentas, aplicativos ou técnicas você utiliza para construir seu material de estudo? 5 - Você acredita que o compartilhamento dos seus processos de estudo na Internet auxiliam o seu aprendizado? Por que? - Com estas questões, portanto, buscou-se compreender a motivação e a compreensão dos usuários em relação aos Studygrams.

\section{Resultados e Discussão}

A análise do discurso enquanto disciplina Linguística busca compreender os sentidos que o sujeito manifesta através do seu discurso para além do que é dito ou escrito. Nesse processo, foi feita uma leitura do texto observando-se atentamente as palavras utilizadas, os sujeitos envolvidos, bem como interesses e circunstâncias, o que auxiliou o estabelecimento de prospecções possíveis a respeito do imaginário da amostra selecionada.

De acordo com análise, de modo geral o studygram parece representar uma forma diferente de utilização do Instagram pelo fato de que o conteúdo compartilhado pode agregar valor para os outros usuários. Identificou-se, portanto, nos usuários dos studygrams, um grande senso de propósito, compartilhamento e coletividade, que converge com o conceito de Pierry Levy(2003) acerca de uma inteligência compartilhada que surge a partir da colaboração dos indivíduos em suas diversidades. Com isto, sugere-se que futuramente a pesquisa possa abranger uma investigação acerca da relação entre os nativos digitais (Prensky 2001) e a inteligência coletiva, visto que os participantes da pesquisa concentram-se numa faixa etária de 15-25 anos e não houve, neste projeto piloto, critério referente a nível de escolaridade.

Com relação à produção autônoma do material de estudo feita pelos usuários, espera-se ampliar a pesquisa relacionando este fato ao conceito de construcionismo em que, segundo Saymour Papert(1994) a construção do conhecimento baseada na realização de uma ação concreta com o uso do computador resulta em um produto palpável. Deste modo, o Studygram pode ser inserido na dimensão social, que aborda a relação da atividade com as relações pessoais e com o contexto sócio-cultural do sujeito. A dimensão social é uma das cinco dimensões que formam a base da teoria construcionista e é evidente que as redes sociais podem ser aliadas na oportunização de valorização das experiências de aprendizado. É necessário, pois, verificar a relação desta dimensão com as demais e o papel da tecnologia em cada uma delas.

Com relação às ferramentas de criação, os usuários relataram uma mescla de recursos analógicos, como lettering e bullet journal, com recursos digitais muitas vezes disponíveis gratuitamente em Smartphones. Para esta questão, sugere-se a expansão da investigação acerca da relação entre os recursos analógicos e os recursos digitais na concepção dos usuários/ educandos. Nesta etapa, uma das possibilidades é a utilização 
VII Congresso Brasileiro de Informática na Educação (CBIE 2018)

Anais do XXIX Simpósio Brasileiro de Informática na Educação (SBIE 2018)

da metodologia de pesquisa-ação para proporcionar a uma amostra de usuários que não possuem Studygram oficinas de lettering e criação de conteúdo com recursos audiovisuais, de forma a possibilitar o contato com a arte, a expressão criativa e a utilização da tecnologia para captura e edição de recursos audiovisuais. Acredita-se que a partir das sugeridas oficinas, seja possível compreender e vivenciar o processo de construção de um Studygram junto com os participantes, bem como criar um mapeamento cognitivo dos mesmos com vistas à análise dos benefícios da construção ativa por meio das redes digitais.

Com relação à motivação, um dos desdobramentos possíveis é a investigação de relações entre o compartilhamento de conteúdo e a chamada motivação científica, visto que os entrevistados alegaram que compartilhar seus processos de estudo nas redes sociais os mantém motivados. É possível, pois, afirmar que a autonomia para criar e o senso de propósito geram motivação suficiente para otimização de aprendizados? Sugere-se, para tanto, uma pesquisa que contemple esta validação de forma experimental, a fim de que se possa, através de dados quantitativos e qualitativos em análise de evolução, no âmbito da Psicologia cognitiva, testar esta hipótese e suas implicações.

\section{Considerações finais e possibilidades futuras}

Este projeto piloto discute sobre uma forma de interação e compartilhamento em redes sociais apoiando processos de ensino/aprendizagem de jovens usuários. A proposição de reflexões com fundamentação neurocientífica e tecnológica demonstra que esta discussão pode ser dotada de rigor científico. O caso dos studygrams - um fenômeno atual e pouco explorado por professores e pesquisadores - também pode vir a ser consolidado como mais uma inovação na forma de aprender, oriunda do avanço tecnológico, visto que este fenômeno pode ser compreendido também como um alerta inconsciente dos jovens não apenas sobre a forma como eles querem representar seus conteúdos, mas também sobre a forma como eles querem aprender e compartilhar seus aprendizados.

É preciso, pois, investigar melhor este processo de forma a verificar suas reais contribuições e implicações para que nós possamos cada vez mais compreender e mediar a nossa interação com tecnologia.

As próximas etapas da pesquisa consistirão na ampliação da amostra para uma compreensão ainda mais ampla do fenômeno a fim de que se possa estabelecer hipóteses e relações a serem discutidas e testadas com aporte interdisciplinar. Indispensável se faz o aporte da neurociência para a compreensão dos processos cognitivos no background dos usuários. Desta forma, pretende-se que a possível utilização desta ferramenta tecnológica no âmbito educacional seja feita de forma comprovadamente cientifica e orientada.

A tecnologia da Informação é hoje aliada da Educação por possibilitar a inventividade, dando espaço para a abstração e a concretude, para o planejamento e para a execução, para o físico e o lógico, para o algoritmo e a heurística, para a percepção e para a reação, para o processo e para a análise, para o imaginário e para a criatividade. Sendo concomitantemente front-end e back-end para a criatividade, espera-se que a tecnologia continue auxiliando cada vez mais a compreensão da nossa cognição e a nossa expressão como sujeitos.

\section{Referências}

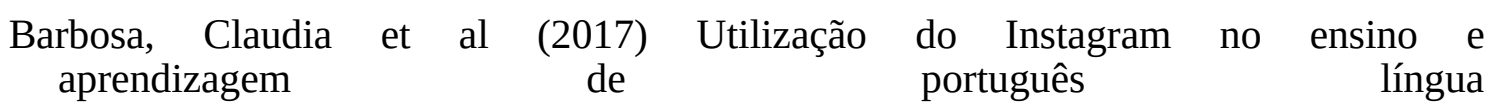


VII Congresso Brasileiro de Informática na Educação (CBIE 2018)

Anais do XXIX Simpósio Brasileiro de Informática na Educação (SBIE 2018)

estrangeira por alunos chineses na

Universidade de Aveiro. Revista Latinoamericana de Tecnología Educativa, 16(1)

Lèvy, P. A inteligência coletiva: por uma antropologia do ciberespaço. 4. ed. São Paulo: Loyola, 2003.

Marques, Welisson. Metodologia de Pesquisa em Análise

Prensky, M. (2001) Digital Natives, Digital Immigrants. MCB University Press. http:// www.marcprensky.com/writing/Prensky\%20\%20Digital\%20Natives,\%20Digital \%20Immigrants\%20 \%20Part1.pdf

Shepherd, T. G.; Saliés, T. G. (2013) O princípio: entrevista com David Crystal. In: SHEPHERD, Tania G.; SALIÉS, Tânia G. (Orgs.). Linguística da internet. São Paulo: Contexto

Papert, Seymour M. (1994). A Máquina das Crianças: Repensando a Escola na Era da Informática.

Teixeira, Simone. M. S. et al (2017) A [sic] uso do Instagram como ferramenta de ensino: um estudo de caso. IV Conedu. https://www.editorarealize.com.br/revistas/conedu/trabalhos/TRABALHO EV073 MD4 SA19 ID6756 13092017191721.pdf 